\title{
Post-partum intrauterine contraceptive device: acceptability and safety
}

\author{
Bhawna Tomar ${ }^{1}$, Vandana Saini ${ }^{2}$, Mamta Gupta ${ }^{3 *}$
}

\begin{abstract}
${ }^{1}$ Department of Obstetrics and Gynecology, Shanti Kumud Hospital, Delhi, India
${ }^{2}$ Department of Obstetrics and Gynecology, Hindu Rao Hospital, Delhi, India

${ }^{3}$ Department of Obstetrics and Gynecology, GL Maternity Hospital, Delhi, India
\end{abstract}

Received: 09 March 2018

Accepted: 03 April 2018

\section{*Correspondence:}

Dr. Mamta Gupta,

E-mail: write2mamta55@gmail.com

Copyright: (C) the author(s), publisher and licensee Medip Academy. This is an open-access article distributed under the terms of the Creative Commons Attribution Non-Commercial License, which permits unrestricted non-commercial use, distribution, and reproduction in any medium, provided the original work is properly cited.

\begin{abstract}
Background: Antenatal period is the ideal time for counselling regarding contraception. PPIUCD is a long term reversible method for unmet need of contraception in women of reproductive age. The objectives of this study were to determine proportion of women accepting PPIUCD insertion, their socio-demographic, obstetrics characteristics, reason for acceptance, denial, rates of expulsion, complications and continuation rate till 10 weeks after insertion.

Methods: A prospective descriptive study on 300 consented women was done in 2012-2013. A structured questionnaire and performa were used to obtain data. PPIUCD (CuT380A) was inserted in these women and were followed up till 10 weeks post insertion.

Results: Out of 300 women counselled, only 85 accepted PPIUCD giving an acceptance rate of 28.33\%. Women who had short inter-conceptional period or those who had previously used interval IUCD were significantly associated with greater acceptance. Fear of pain, heavy bleeding and infertility when planning next pregnancy were the most common reasons for denial. Continuation rate was $86.89 \%$ at 10 th week after insertion. No major complication was observed i.e. perforation, infection and pregnancy.

Conclusions: PPIUCD is quite safe method of contraception. Adequate counselling and clarification of myths associated with PPIUCD use can help acceptance and meet the unmet needs of contraception in post-partum period and even later in reproductive age women.
\end{abstract}

Keywords: Acceptance for PPIUCD, Complications of PPIUCD, Continuation after PPIUCD, denial for PPIUCD, PPIUCD, Safety of PPIUD

\section{INTRODUCTION}

India stands as the second largest populated country in the world with a population of 1.32 billion estimated in 2017. It is projected to contribute $17.74 \%$ to world's population in $2018 .{ }^{1} 27 \%$ of births are spaced less than 24 months apart. Short birth intervals less than 24 months are associated with increased health risk for mother and baby. $^{2}$ Any pregnancy that occurs within 24 months of last child birth increases the risk of adverse outcomes for mother, her baby and her new pregnancy like anemia, abortions, premature labor, PPH, low birth weight babies, fetal loss and maternal death. ${ }^{3} 61 \%$ of women in $0-23$ months postpartum have an unmet need for family planning in a data from recent Demographic and Health Surveys (DHS) conducted in 21 low- and middle-income countries to examine patterns of inter-pregnancy intervals, unmet need, pregnancy risk where family planning method use only $31 \% .{ }^{4}$ Postpartum women express a desire to prevent pregnancy during first two years after delivery but the majority are not using any contraception (UNMET NEED). Antenatal, postnatal 
and immunization visits at health facilities are opportunities for health care providers for counselling on family planning methods. Post-partum IUCD insertion overcomes multiple barriers to service provision. ${ }^{5}$ It is a long term reversible method and may be an alternative to tubectomy. Its efficacy, compliance is high does not require daily self-administration and thus women can effectively avoid unintended pregnancies. Post-insertion symptoms are masked by the normal postpartum cramping and lochia. Postpartum insertion is convenient both for the women and the provider. Follow up can be scheduled along with immunization visits. A study on PPIUCD therefore, was done with the aim of future scope of the method, reasons for its acceptability, denial and associated complaints and complications.

\section{METHODS}

The study was conducted in the department of Obstetrics and Gynecology, Hindu Rao Hospital and associated NDMC Medical College, Delhi from December 2012 to November 2013. Ethical committee of the institution approved the study.

A total of 300 women attending antenatal OPD, admitted in early labor in labor ward and postnatal ward were enrolled after taking consent to participate in the study. A structured questionnaire was used to obtain data. This questionnaire included four main areas

- Socio demographic information

- Antenatal history, previous obstetric history and future pregnancy desires

- Previous menstrual history, contraceptive history, contraceptive preferences and awareness regarding PPIUCD

- Reasons of acceptance or decline.

They were counselled regarding adopting PPIUCD as a method for contraception. Women who were for a scheduled cesarean section and missed counselling previously were counselled prior to cesarean operation about intra cesarean IUCD insertion. All women who accepted PPIUCD, reconfirmation of their choice was done, and consent was taken for insertion of PPIUCD. All these women after exclusion criteria, had CuT 380A inserted.

\section{Exclusion criteria}

Women with fibroids, chronic pelvic pain, copper allergy, rupture of membranes $>18$ hours, unresolved $\mathrm{PPH}$, extensive genital trauma following delivery, sepsis and bleeding disorders.

PPIUCD was inserted either post placental i.e. within 10 min. of placental delivery; postpartum i.e. upto 48 hours of delivery or intra-cesarean. They were asked to come for follow up visits at six and ten weeks of insertion corresponding with their baby's immunization visits. A
PPIUCD follow up card was given to all the parturients after insertion of PPIUCD. This included instructions about recognizing expulsion, postpartum warning signs i.e. unusual abdominal or pelvic pain, bleeding, unusual vaginal discharge or fever. PPIUCD card also contained information on the date of insertion, follow up visit, date of expiry of the IUCD and a telephone number for any query. These women were also advised to call on phone or come back any time in emergency department if they had any concern, experience any warning sign or if the IUCD is expelled.

At follow up, history of fever, pain in abdomen, foul smelling vaginal discharge, spotting and bleeding per vaginum was recorded. General examination and abdominal examination for suprapubic tenderness, involution of the uterus was carried out. A speculum examination was performed to check if the strings were visible or any discharge present. The visible IUCD strings were trimmed at approximately $3 \mathrm{cms}$. from cervical os. A per vaginum examination was then done to assess for uterine involution and adnexal tenderness. Women who reported expulsion of the IUCD or those in whom strings were not visible had a pelvic ultrasound for localization.

Data entry was done using Statistical Package for the Social Sciences (SPSS) version 17.0 for statistical analysis. Descriptive data were summarized as percentages. The Chi-square test was used to measure the strength of associations between variables. A p-value of $<0.05$ was considered to be statistically significant.

\section{RESULTS}

A total of 300 women were counselled, 150 from antenatal OPD, 90 admitted in early labor, 60 women admitted in postpartum ward. Out of these, only 85 women accepted PPIUCD acceptance rate of $28.33 \%$, rest of 215 women declined PPIUCD insertion. Literacy and religion of the women, future desire for the child, previous usage of contraception and awareness of PPIUCD were statistically significant factors for accepting PPIUCD by post-partum women (Table 1).

Reasons for declining or refusing for PPIUCD is given in Table 2 The commonest reason for declining PPIUCD was found to be preference to use natural contraceptive methods and lactational amenorrhoea method. They thought that they will not become pregnant during lactation period.

Many women did not want use of immediate contraceptive method. Some wanted to discuss with their family members and some were satisfied with previous methods of contraception. The percentages were more than $100 \%$ as there were more than one response by some women who declined PPIUCD. 
Amongst the decliners for PPIUCD, preferences for other forms of contraception has been analyzed in Table 3. The most preferred method was LAM method followed by OCPs.

Table 1: Acceptors and decliners according to demography and contraceptive history.

\begin{tabular}{|c|c|c|c|c|c|}
\hline \multirow[t]{2}{*}{ Parameter } & \multicolumn{2}{|c|}{$\begin{array}{l}\text { Acceptors } \\
(\mathbf{n}=\mathbf{8 5})\end{array}$} & \multicolumn{2}{|c|}{$\begin{array}{l}\text { Decliners } \\
(\mathrm{n}=215)\end{array}$} & \multirow{2}{*}{$\begin{array}{l}\mathbf{P} \\
\text { value }\end{array}$} \\
\hline & $\mathbf{N}$ & $\%$ & $\mathbf{N}$ & $\%$ & \\
\hline \multicolumn{5}{|l|}{ Age in years } & \multirow{5}{*}{0.084} \\
\hline$<20(n=26)$ & 2 & 7.7 & 24 & 92.3 & \\
\hline $21-25(n=171)$ & 53 & 31.0 & 118 & 69 & \\
\hline $26-30$ years $(n=81)$ & 25 & 30.9 & 56 & 69.1 & \\
\hline$>30$ years $(n=22)$ & 5 & 22.7 & 17 & 77.3 & \\
\hline \multicolumn{5}{|l|}{ Education } & \multirow{5}{*}{0.014} \\
\hline Illiterate $(n=94)$ & 21 & 22.3 & 73 & 77.7 & \\
\hline $\begin{array}{l}\text { Primary school } \\
(n=156)\end{array}$ & 44 & 28.2 & 112 & 71.8 & \\
\hline $\begin{array}{l}\text { Secondary school } \\
(\mathrm{n}=30)\end{array}$ & 19 & 47.5 & 21 & 52.5 & \\
\hline College $(n=10)$ & 1 & 10.0 & 9 & 90.0 & \\
\hline \multicolumn{5}{|l|}{ Religion } & \multirow{5}{*}{0.004} \\
\hline Hindu $(\mathrm{n}=177)$ & 59 & 33.3 & 118 & 66.7 & \\
\hline Muslim (n =107) & 18 & 16.8 & 89 & 83.2 & \\
\hline $\operatorname{Sikh}(\mathrm{n}=11)$ & 6 & 54.5 & 5 & 45.5 & \\
\hline Christian $(\mathrm{n}=5)$ & 2 & 40 & 3 & 60 & \\
\hline \multicolumn{5}{|c|}{ Occupation } & \multirow{3}{*}{0.002} \\
\hline Housewife $(n=267)$ & 68 & 25.5 & 199 & 74.5 & \\
\hline $\begin{array}{l}\text { Working women } \\
(\mathrm{n}=33)\end{array}$ & 17 & 51.5 & 16 & 48.5 & \\
\hline \multicolumn{5}{|l|}{ Parity } & \multirow{4}{*}{0.022} \\
\hline $\mathrm{p} 1(\mathrm{n}=120)$ & 29 & 24.2 & 91 & 75.8 & \\
\hline $\mathrm{p} 2(\mathrm{n}=112)$ & 42 & 34.4 & 70 & 65.6 & \\
\hline$\geq \mathrm{p} 3(\mathrm{n}=68)$ & 14 & 20.6 & 54 & 79.4 & \\
\hline \multicolumn{5}{|c|}{ Future desire for child } & \multirow{3}{*}{0.031} \\
\hline Yes $(n=161)$ & 54 & 33.5 & 107 & 66.5 & \\
\hline No $(n=139)$ & 31 & 22.3 & 108 & 77.7 & \\
\hline \multicolumn{5}{|c|}{ Previous contraception } & \multirow{3}{*}{0.001} \\
\hline Not used $(n=247)$ & 47 & 19.0 & 200 & 81.0 & \\
\hline Used $(n=53)$ & 38 & 71.7 & 15 & 28.3 & \\
\hline \multicolumn{5}{|c|}{ Awareness of PPIUCD } & \multirow{3}{*}{0.0001} \\
\hline Aware $(n=36)$ & 21 & 58.3 & 15 & 41.7 & \\
\hline Not aware $(n=264)$ & 64 & 24.2 & 200 & 75.8 & \\
\hline \multicolumn{5}{|c|}{ Timing of counselling } & \multirow{4}{*}{0.585} \\
\hline Antenatal $(n=150)$ & 46 & 30.7 & 104 & 69.3 & \\
\hline Early labor $(n=90)$ & 22 & 24.4 & 68 & 75.6 & \\
\hline postpartum $(n=60)$ & 17 & 28.3 & 43 & 71.7 & \\
\hline
\end{tabular}

Table 4 depicts reasons for acceptance for PPIUCD by women who were counselled. It can be seen that the commonest reason for acceptance was that it is a long term reversible method. Other reason was that women do not perceive it as a surgical method with no incision required anywhere in body (Table 5). The percentages are more than $100 \%$ as there were more than one response by some women who accepted PPIUCD.
Table 2: Reasons for decline for PPIUCD (N=215).

\begin{tabular}{|lll|}
\hline Reasons for decline & N & $\%$ \\
\hline $\begin{array}{l}\text { Wants to use lactational amenorrhoea } \\
\text { method }\end{array}$ & 81 & 37.7 \\
\hline Prefer to use natural methods except lam & 61 & 28.4 \\
\hline Do not want contraception immediately & 61 & 28.4 \\
\hline $\begin{array}{l}\text { Satisfied with contraceptive method used } \\
\text { previously }\end{array}$ & 46 & 21.4 \\
\hline Want to discuss with family members & 45 & 20.9 \\
\hline Fear of pain and heavy bleeding & 38 & 17.7 \\
\hline Fear of obesity & 32 & 14.9 \\
\hline Refusal by relatives influencing the decision & 18 & 8.4 \\
\hline Refusal by partner & 14 & 6.5 \\
\hline Affects future fertility & 9 & 4.1 \\
\hline Religious beliefs & 9 & 4.1 \\
\hline Infrequent sex & 9 & 4.1 \\
\hline $\begin{array}{l}\text { Not enough knowledge and experience of } \\
\text { PPIUCD }\end{array}$ & 6 & 2.8 \\
\hline Fear of cancer & 4 & 1.9 \\
\hline Previous bad experience & 4 & 1.9 \\
\hline Interferes with sexual intercourse & 2 & 0.9 \\
\hline
\end{tabular}

Table 3: Contraceptive preferences amongst decliners of PPIUCD $(\mathbf{N}=215)$.

\begin{tabular}{lll}
$\begin{array}{lll}\text { Preferred contraceptive method in } \\
\text { decliners }\end{array}$ & N & $\%$ \\
\hline LAM & 54 & 25.1 \\
\hline OCP & 33 & 15.3 \\
\hline Interval IUCD & 18 & 8.4 \\
\hline Male condoms & 15 & 7 \\
\hline DMPA & 8 & 3.7 \\
\hline Implants & 2 & 0.9 \\
\hline None & 36 & 16.7 \\
\hline
\end{tabular}

Table 4: Reasons for acceptance for PPIUCD.

\begin{tabular}{|lll|}
\hline Reason for acceptance & N & $\%$ \\
\hline Long term, reversible method & 36 & $42.3 \%$ \\
\hline No incision required & 32 & $37.6 \%$ \\
\hline Fewer visit to health facility & 16 & $18.8 \%$ \\
\hline No need to take orally & 12 & $14.1 \%$ \\
\hline No need to remember daily or weekly & 10 & $11.8 \%$ \\
\hline No interference with breast feeding & 3 & $3.5 \%$ \\
\hline Previous copper t use & 2 & $2.3 \%$ \\
\hline
\end{tabular}

Table 5: Reasons for not inserting PPIUCD after initial acceptance.

\begin{tabular}{|lll|}
\hline Reasons for not inserting ppiucd $(\mathbf{n}=\mathbf{1 2})$ & $\mathbf{N}$ & $\%$ \\
\hline Did not consent for insertion of PPIUCD & 4 & 4.7 \\
\hline PPH, unresolved & 6 & 7.0 \\
\hline Low platelet counts & 2 & 2.3 \\
\hline
\end{tabular}

85 women accepted for insertion of PPIUCD, out of these only 73 women got PPIUCD inserted. Reasons for not inserting PPIUCD $(n=12)$ after initial acceptance after counselling is given in Table 5. Number of women who 
had post-placental insertion i.e. within 10 minutes of placental expulsion, post-partum insertion i.e. after 10 minutes of placental expulsion but before 48 hours, and intra-cesarean insertion were $35,17,21$ respectively (Table 6).

Table 6: Timing of insertion and follow-up till 10 weeks of insertion.

\begin{tabular}{|lll|}
\begin{tabular}{|l} 
Type of \\
insertion
\end{tabular} & $\begin{array}{l}\text { No. of PPIUCD } \\
\text { insertion } \\
\mathbf{N}=73\end{array}$ & $\begin{array}{l}\text { Women followed } \\
\text { up till 10 weeks } \\
(\mathbf{N}=61)\end{array}$ \\
\hline Post-placental & 35 & 28 \\
\hline Post-partum & 17 & 13 \\
\hline Intracesarean & 21 & 20 \\
\hline
\end{tabular}

These women were followed up at 6 weeks and 10 weeks post-partum. Maximum number of women got PPIUCD inserted post-placentally. The follow-up rate was maximum after intra-cesarean insertion (Table 6).

Table 7: Continuation/removal/expulsion details of PPIUCD at follow up.

\begin{tabular}{|lll|}
\hline $\begin{array}{l}\text { Details at } 10 \text { weeks follow up of } \\
\text { PPIUCD (n=61) }\end{array}$ & $\mathbf{N}=61 \%$ \\
\hline $\begin{array}{l}\text { Spontaneously expulsion of PPIUCD } \\
\text { Retained PPIUCD }\end{array}$ & 4 & 6.6 \\
\hline $\begin{array}{l}\text { PPIUCD removed at health centers } \\
\text { (for pain in abdomen/bleeding pv) }\end{array}$ & 3 & 4.9 \\
$\begin{array}{l}\text { Removal of PPIUCD during follow up } \\
\text { (women insisting for removal for pain } \\
\text { in abdomen) }\end{array}$ & 2 & 3.3 \\
$\begin{array}{l}\text { Reinsertion of PPIUCD (in women } \\
\text { who had spontaneous expulsion) }\end{array}$ & 1 & 1.6 \\
\hline Net continuation of PPIUCD & 53 & 86.9 \\
\hline
\end{tabular}

Table 8: Complaints / complications in PPIUCD at follow up.

\begin{tabular}{|c|c|c|c|}
\hline Complaints & $\mathbf{N}$ & $\%$ & Intervention required \\
\hline Backache & 4 & 6.6 & $\begin{array}{l}\text { Analgesics, post-natal } \\
\text { exercises }\end{array}$ \\
\hline $\begin{array}{l}\text { Thread } \\
\text { felt at vulva }\end{array}$ & 11 & 18 & Thread cut short \\
\hline $\begin{array}{l}\text { Pain in } \\
\text { abdomen }\end{array}$ & 7 & 11.5 & $\begin{array}{l}\text { PID ruled out, counselled, } \\
\text { symptomatic treat. } 2 \\
\text { women insisted for removal }\end{array}$ \\
\hline Bleeding PV & 4 & 6.6 & $\begin{array}{l}\text { Counselling, Tranexamic } \\
\text { acid }\end{array}$ \\
\hline $\begin{array}{l}\text { Vulval } \\
\text { irritation }\end{array}$ & 7 & 11.5 & $\begin{array}{l}\text { IUCD thread was seen at } \\
\text { vulva, cut short }\end{array}$ \\
\hline $\begin{array}{l}\text { Pain in abdomen } \\
\text { and spotting on } \\
\text { and off }\end{array}$ & 3 & 4.9 & $\begin{array}{l}\text { PID ruled out, counselled, } \\
\text { tranexamic acid }\end{array}$ \\
\hline Lost strings & 2 & 3.3 & $\begin{array}{l}\text { USG confirmed IUCD in } \\
\text { situ. Counselled to } \\
\text { continue to use }\end{array}$ \\
\hline
\end{tabular}

During follow up of these women, upto 10 weeks postinsertion, it was found that PPIUCD was retained in $93.44 \%(\mathrm{n}=57)$ women. Expulsion rate was $6.56 \%$ $(n=4)($ Table 7$)$. The 4 women in whom PPIUCD was expelled spontaneously, 3 had post-partum insertion and only 1 had post-placental insertion.

All women with complaints related to PPIUCD were examined during follow-up. No serious complaint or complication was observed. All women were relieved by symptomatic treatment, counselling and non-invasive investigations i.e. USG. Two women had removal of PPIUCD at facility, with complaint of pain in abdomen and insisted for removal (Table 8).

\section{DISCUSSION}

Postpartum period is one of the critical times when women are vulnerable to unintended pregnancy, once fertility returns. PPIUCD is a good option for these women. Therefore, its acceptance and safety has been the focus of our study. Altogether, 300 women were counselled, 150 during antenatal period, 90 during early labor, 60 in postpartum period. Out of these, PPIUCD was accepted by $85(28.33 \%)$ women. Majority of women were in the age group of $20-25$ years $(57 \%)$ with mean age of $24.17(\mathrm{SD} \pm 4.12)$ years. In a study in Embu district, Kenya the mean age of clients $(27 \pm 6.6$ years) was slightly higher than in our study. ${ }^{6}$ The mean age of women in Tanzanian study was $27.6 \pm 5.68$ years, slightly higher than our study. ${ }^{7}$ However, no significant association between age and acceptance of PPIUCD was found ( $\mathrm{p}$ value 0.084 ).

Majority of those who accepted PPIUCD were para 2 with an acceptance rate of $34.4 \%$ in our study. In a review article by Kulier et al women with 1 child chose IUCD as their preferred method of contraception. ${ }^{8}$ Mohamed SA et al reported that majority of acceptors were grand multiparas. ${ }^{9}$ Perhaps multipara women accepted sterilization more in our population.

Working women had a significantly higher acceptance for PPIUCD in the present; study ( $p$ value 0.002). Though, $80 \%(n=267)$ of the population by occupation were housewives; yet, the acceptance rate of PPIUCD was significantly high in working women compared to housewives $(51.5 \%$ versus $25.5 \%)$. In a Tanzanian study, no significant association between occupation and acceptance was found. ${ }^{7}$

Literacy of women was found to be a significant factor for acceptance of PPIUCD ( $p$ value 0.014). Illiterate women had an acceptance rate of $22.3 \%$ while literates had acceptance rate of $31.1 \%$ This was similar to a study done in Egypt by Mohamed SA et al where women with no formal education had an acceptance of $9.4 \%$ while those with formal education was $19.4 \% .^{9}$ Women with secondary school education had an acceptance rate of $63.33 \%$ in the present study compared to primary school 
and colleges where the acceptance rate of PPIUCD was $28.2 \%$ and $10 \%$ respectively. This is in corroboration with a study done in Zimbabwe where acceptance was more among women who completed secondary education (12 years or more) ${ }^{10}$ However, no difference among primary and secondary education was shown in Tanzanian study. ${ }^{7}$

In the present study it was seen that only $17.7 \% \quad(n=53)$ women had history of some contraception usage. Acceptance rate for PPIUCD was significantly high in these women $(\mathrm{P}=0.001)$ who had used some contraception in the past. Prior contraceptive usage by women was $64.36 \%, 67.5 \%$ respectively in study by Mohamed et al and in a Tanzanian study which is quite high compared to ours. ${ }^{9,7}$ PPIUCD is a relatively new method of contraception in the community and media and FP projection is still low for PPPIUCD in our country.

Women who were aware of PPIUCD had a significantly higher acceptance rate ( $p$ value 0.0001 ) in our study compared to those who were not aware of PPIUCD (58.3\% versus $24.2 \%)$. Acceptance rate therefore, can be increased by increasing awareness of PPIUCD through counselling in the antenatal clinics, during early labor or in post-natal ward. There is a need for promoting awareness at community level and by health administrators by advertisements and awareness programmes.

Extrapolating the data of acceptors by literacy and awareness of contraception from present study, it appears that literacy does not transform directly to awareness and acceptance of PPIUCD. Out of 36 women aware of PPIUCD, 21 accepted it; whereas out of 196 literate women only 54 accepted PPIUCD (27.5\%). Hence, awareness about PPIUCD is a very important factor for its acceptance.

The commonest reason for accepting PPIUCD by the women was that it is a long term, reversible method. Similar observations were made by Sharma A. et al. ${ }^{11}$ The next common reason for its acceptance was that women did not perceive PPIUCD insertion as a surgical procedure as no incision is required for its insertion.

Among those women who declined the PPIUCD $(71.67 \%)$ more than one third preferred LAM method for immediate contraception, $20.9 \%$ women wanted to discuss with their partners not accompanying them, $21.3 \%$ were satisfied with their non PPIUCD contraceptive method in the present study. In a study done in Egypt, among the $71.1 \%$ women who refused PPIUCD, planning another pregnancy in the near future $(34.3 \%)$ was the most common reason followed by preference of interval IUCD $(30.2 \%)$ and LAM method $(9.3 \%){ }^{9}$ Complications from previous use of IUCD $(9.7 \%)$ or denial by partners $(3.4 \%)$ and relatives were some other reasons. ${ }^{9}$ Priya et al in her study on PPIUCD has reported that the most common reason affecting the readiness for PPIUCD insertion was lack of involvement of husband in counselling during antenatal period, regarding the need for birth spacing and benefits of PPIUCD. ${ }^{12}$ This reveals the importance of counselling of husband, family members and participation in decision making. In our study, even the husband felt need to discuss with elders in the family and $14.88 \%$ women declined because of partner and relatives' denial. Relatives could be biased and resistant for PPIUCD method because of the myths and misconceptions associated with IUCDs. Therefore, involvement of husband and other family members should become an integral part of counselling.

Only 73 women out of 85 acceptors in our study, were inserted PPIUCD. Most of the insertions were postplacental $(47.95 \%)$ followed by post-partum insertions $(28.77 \%)$ and intra-cesarean insertions $(23.29 \%)$. These observations are similar to study by Celen et al where $74 \%$ PPIUCD were inserted following vaginal deliveries and $26 \%$ were inserted following cesarean deliveries. ${ }^{13}$ In the present study all PPIUCD were inserted by doctors; however, in a study at Kenya, most of the providers trained were midwives, $56 \%$ of insertions had postplacental insertions, $42 \%$ post-partum and only $2 \%$ were intracesarean. $^{6}$

In this study the total number of women who could be followed up till 10 weeks post-insertion were $73 \%(\mathrm{n}=$ 61). Celen et al in his study found a follow up of $89 \%$, while in Egypt study the follow up rate was $90 \%$, in 2 follow up visits. ${ }^{14,13}$

In our study, the number of expulsion of PPIUCD were observed in $6.56 \%(n=4)$ women. One of them had post placental IUCD and 3 of them had post-partum IUCD. Similar observation was made by Celen C et al in 2004 who found expulsion rates of the post-placental PPIUCD at 6 weeks follow up as $6.4 \%$ and cumulative expulsion rate of $12.3 \%$ at 1 year. ${ }^{13}$ The expulsion rates of IUDs during immediate puerperium and after interval insertion were 16 and $2.7 \%$, respectively. ${ }^{14}$ In a study by S Mishra on 564 PPIUCD insertions, an expulsion rate of $8.99 \%$ was observed; $0.69 \%$ were expelled within 7 days, $7.6 \%$ were expelled between 7-44 days and only 0.66\% were expelled after 4 weeks. ${ }^{15}$ Expulsion of PPIUCD has been reported in the first few weeks after insertion. ${ }^{15}$ A lower risk of expulsion is reported for insertions done within 10 minutes of delivery than for those done between 10 minutes and hospital discharge. ${ }^{16}$ Good techniques can reduce expulsion.

Two cases (3.27\%) among those inserted with PPIUCD had lost strings during the follow up period in our study. Pelvic ultrasound confirmed that the IUCD was in situ. This indicated possible retraction or curling of the strings into the endocervical canal or uterine cavity. In a Tanzanian study, incidence of lost strings was $5.3 \% .^{7}$ In a 3 year follow up study of 290 PPIUCD women by Mishra $\mathrm{S}$ it was seen that the strings were visible in only 424 
cases, and 266 had missing strings at the beginning of the study. However, there was spontaneous descent of the strings in 138 of the 266 missing strings cases. At the end of 3 years, strings were visible in 562 and missing in 128 cases. Curled strings in cervical canal and retraction into uterine cavity were the commonest causes for missing strings. ${ }^{17}$ Barala et al has reported missing strings in $8 \%$ in their study. ${ }^{18}$

In our study 5 women $(6.8 \%)$ had removal of PPIUCD for pain in abdomen and bleeding PV. This is in corroboration with study by Barala et al who reported a removal rate of $6 \% .{ }^{18}$ Morrison $\mathrm{C}$ et al in their study on the clinical outcomes of two early post-partum IUD programmes in Africa found that removal occurred in $1 \%$ and $7 \%$ of Kenyan and Malian acceptors respectively. ${ }^{19}$

Continuation rate of PPIUCD in our study was $86.9 \%$. This was similar, as reported in a study in Embu District of Kenya, where a continuation rates of $87.6 \%$ at 6 months has been reported. ${ }^{6} \mathrm{~A}$ higher continuation rate of $92 \%$ has been reported at 6 months follow up by Barala et al. ${ }^{18}$

In the present study no women had pelvic inflammatory disease, perforation, pregnancy or any other complication. All women who had complaints were examined and all of them responded well to conservative treatment. No woman required any major intervention for any complaint/ complication. Thus, PPIUCD is quite safe contraceptive option for post-partum women.

\section{CONCLUSION}

PPIUCD is a safe, long acting reversible contraceptive method having no reported incidence of perforation with low rates of expulsion and pelvic infection. Promotion of health education, awareness of PPIUCD as a contraceptive method, eliminating apprehension and myths related with the method through effective communication at community level workers and media is the need of the hour. The provision of PPIUCD is feasible and can decrease the unmet need for contraception.

Funding: IUCD (CuT 380A) were supplied free of cost to all women by Government of India

Conflict of interest: None declared

Ethical approval: The study was approved by the Institutional Ethics Committee

\section{REFERENCES}

1. Population of the world. Available at https://www.livepopulation.com/country/india.html

2. National Family and Health Survvey (NFHS-4), 2015-2016. Ministry of Health and Family Welfare. Government of India. Available at http://rchiips.org/NFHS/NFHS-4Reports/India.pdf
3. Rutstein SO. Effects of preceding birth intervals on neonatal, infant and under-five years mortality and nutritional status in developing countries: evidence from the demographic and health surveys. Int $\mathbf{J}$ Gynecol Obstet. 2005;89(S1).

4. Moore Z, Pfitzer A, Gubin R, Charurat E, Elliott L, Croft T. Missed opportunities for family planning: an analysis of pregnancy risk and contraceptive method use among postpartum women in 21 low- and middle-income countries. Contracept. 2015;92(1):319

5. Maternal and Child Health Integrated Program. MCHIP India. Achievements 2009-2014. USAID. Available at https://www.mchip.net/sites/default/files/MCHIP_In dia\%20brochure.pdf

6. Charurat E, Ayuyo CM, Muthoni J, Kamunya R, Archer L, Koskei N, et al. An assessment of postpartum intrauterine contraceptive device services in Embu, Kenya. February 2011. Available at https://www.k4health.org/sites/default/files/Kenya\% 20PPIUCD\%20Assessment\%20Report\%204Feb11_ Final.pdf

7. Ram A. Acceptability and safety of postpartum intrauterine contraceptive device among parturients at Muhimbili National Hospital, Tanzania, Department of Obstetrics and Gynecology of the Muhimbili University of Health and Allied Sciences. 2012.

8. Agarwal N, Gupta M, Sharma A, Arora R. Antenatal counselling as a tool to increase acceptability of postpartum intrauterine contraceptive device insertion in a tertiary care hospital. Int $\mathbf{J}$ Reprod Contracept Obstet Gynecol. 2015;4(4):1137-41.

9. Mohamed SA, Kamel MA, Shaaban OM, Salem HT. Acceptability for the use of postpartum intrauterine contraceptive devices. Assuit Experience Medical Principles and Practice. 2003;12:170-5.

10. Thomas D, Maluccio J. Fertility, contraceptive choice, and public policy in Zimbabwe. The World Bank economic review. 1996;10(1):189-222.

11. Sharma A, Gupta V. A study of awareness and factors affecting acceptance of PPIUCD in SouthEast Rajasthan. Int J Community Med Public Health. 2017;4(8):2706-10.

12. Sanskriti P, Tuteja A, Mittal P, Diwan R, Suri J, Kumar A. Exploring reasons behind low acceptance for PPIUCD in postnatal women. New Indian J Surg. 2011;2(4):246.

13. Celen S, Möröy P, Sucak A, Aktulay A, Danisman N. Clinical outcomes of early postplacental insertion of intrauterine contraceptive devices. Contracept. 2004;69(4):279-82.

14. Rosales BF, Zamudio AME, Montero CMde L, Ortiz HME, Ruiz LMA. Factors for expulsion of intrauterine device Tcu380A applied immediately postpartum and after a delayed period. Rev Med Inst Mex Seguro Soc. 2005;43(1):5-10.

15. Mishra S. Evaluation of safety, efficacy, and expulsion of post-placental and intra-cesarean 
insertion of intrauterine contraceptive devices (PPIUCD). J Obstet Gynaecol India. 2014;64(5):33743.

16. United nations population information network. IUD insertion timing vital in postpartum use. Family Health International. 1996;16(2). Available at http://www.un.org/popin/popis/journals/network/net work162/time162.html

17. Mishra S. Tale of the tails, the missing postpartum IUCD strings. J Obstet Gynecol India. 2017;67(3):202-7.

18. Barala S, Maheshwari S, Sharma P. Analysis of awareness, acceptance, safety and continuation rate of post-placental and intra-caesarean insertion of intrauterine contraceptive device. Int $\mathrm{J}$ Reprod Contracept Obstet Gynecol. 2017;5(6):1974-80.

19. Morrison C, Waszak C, Katz K, Diabaté F, Mate EM. Clinical outcomes of two early postpartum IUD insertion programs in Africa. Contracept. 1996;53(1):17-21.

Cite this article as: Tomar B, Saini V, Gupta M. Post-partum intrauterine contraceptive device: acceptability and safety. Int J Reprod Contracept Obstet Gynecol 2018;7:2011-7. 